\title{
Breeding new seedless grape by means of in vitro embryo rescue
}

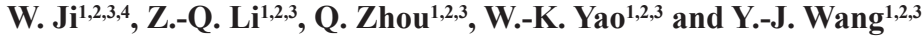 \\ ${ }^{1}$ College of Horticulture, Northwest A\&F University, Yangling, Shaanxi, \\ P.R. China \\ ${ }^{2}$ Key Laboratory of Horticultural Plant Biology and Germplasm Innovation \\ in Northwest China, Ministry of Agriculture, Yangling, Shaanxi, P.R. China \\ ${ }^{3}$ State Key Laboratory of Crop Stress Biology in Arid Areas, \\ Northwest A\&F University, Yangling, Shaanxi, P.R. China \\ ${ }^{4}$ College of Horticulture, Shanxi Agricultural University, Taigu, Shanxi, \\ P.R. China \\ Corresponding author: Y.-J. Wang \\ E-mail: wangyuejin@263.net / yuejinwanglab1@163.com
}

Genet. Mol. Res. 12 (1): 859-869 (2013)

Received October 31, 2012

Accepted January 29, 2013

Published March 26, 2013

DOI http://dx.doi.org/10.4238/2013.March.26.1

\begin{abstract}
This project aimed at breeding new seedless grape cultivars by embryo rescue through three hybridization methods: 1) using cross-breeding between seedless Vitis vinifera cultivars and wild Chinese Vitis spp; 2) crossing with two seedless cultivars, and 3) hybridization between grapes of different ploidy. Genotype, sampling times, and media were confirmed to play important roles in this system. Among the different genotypes, the productions of hybrid plants were significantly different, ranging from $23.0 \%$ (Ruby Seedless $x$ Black Olympia) to only $1.1 \%$ (Pink Seedless x Beichun), except for the combinations from which no surviving seedlings were obtained. We got the best sampling times, in days after flowering (DAF), from the following different combinations: 'Flame Seedless x Beichun'
\end{abstract}


(39 DAF); 'Blush Seedless x Shuangyou' (54 DAF); 'Pink Seedless x Beichun' (54 DAF); 'DA7 x Shuangyou' (44 DAF); 'Blush Seedless x Thompson Seedless (54 DAF)'; 'Pink Seedless x Flame Seedless' (54 DAF); 'DA7 x Blush Seedless' (44 DAF); 'Ruby Seedless x Black Olympia' (63 DAF); 'DA7 x Jingyou' (44 DAF); 'Flame Seedless $\mathrm{x}$ Fujiminori' (39 DAF), and 'Big Black x Kyoho' (72 DAF). The highest rates of embryo formation $(13.2 \%)$ and plant development (90.1\%) were found when ovules were cultured in MM4 with 500 $\mathrm{mg} / \mathrm{L}$ mashed banana. Conversely, they were reduced by addition of plant growth regulators. Seven new hybrids were successfully obtained. As a result of early nuclear-free character and ploidy level identification, 11 seedless grape lines, and 3 triploid and 2 haploid grape lines were obtained.

Key words: Grapevine; Embryo rescue; Seedless grapes; Stenospermocarpy; Hybridization

\section{INTRODUCTION}

China is one of the centers of origin of Vitis species, with many disease-resistant resources (He et al., 1991; He and Luo, 1994; Wang et al., 1995, 1998; Tian et al., 2008; Tang et al., 2009). These wild Vitis spp do not have a foxy flavor, a limiting factor for the use of many North American species in grape breeding programs (Alleweldt and Possingham, 1988). 'Beichun' and 'Shuangyou', two representatives of the wild type, are usually used as pollen parents because of their higher hybridization affinity with Vitis vinifera (Wang et al., 1995; Tian et al., 2008; Tang et al., 2009). Besides good resistance to chilling, moisture, and other environmental stresses (Wang et al., 1998), 'Beichun' also exhibits a significantly higher level of resistance to both downy mildew and anthracnose compared with its wild parent (Liu et al., 2002; Liu and Li, 2004). 'Shuangyou' has good resistance to chilling and anthracnose. Thus, it is possible to use crossing to integrate the fungal disease-resistant traits of the wild Chinese Vitis spp into seedless $V$. vinifera, resulting in fungal disease-resistant seedless grapes.

Seedlessness in $V$. vinifera $\mathrm{L}$. cv. Thompson Seedless is due to stenospermocarpy (Stout, 1936), in which pollination and fertilization occur but the embryos abort. It refers to the grape cultivars that have no seeds or are parthenocarpic, and the embryos or endosperms of parthenocarps are aborted after pollination. Hence, conventional breeding methods cannot be followed for its improvement. Earlier in 1982, Ramming and Emershad first reported that stenospermic grapes could generate plants via ovule culture. Since then, this embryo rescue technique has been widely applied to embryo germination of seedless grape cultivars in cross-breeding programs (Emershad and Ramming, 1984; Spiegle-Roy et al., 1985; Gray et al., 1990; Ponce et al., 2000; Bharathy et al., 2005; Tian et al., 2008; Tang et al., 2009; Singh et al., 2011). Nowadays, in vitro embryo rescue in grape breeding projects assures breeding efficiency by curtailing 6 to 8 years in the development of seedless grape cultivars (Singh et al., 2011), and the adoption of seeded cultivars as female parents has been replaced by using stenospermic grapes as females directly. 
In addition, the cross between grapes of different ploidy was also an effective way to obtain new seedless grape cultivars by the embryo rescue technique (Yamashita et al., 1998; Bessho et al., 2000; Bharathy et al., 2005; Tian et al., 2008; Sun et al., 2011). It has been proven that it was easier to harvest hybrid progeny when using diploids as female parents (Guo et al., 2010). Sun et al. (2011) also assumed that the ovule fertility of tetraploids was lower than that for diploids. Our earlier study indicated that $4 \mathrm{X}$ x $2 \mathrm{X}$ had lost their germinability and no seedlings were obtained. Therefore, the diploids were used as female parents in our experiment.

On the basis of more than 10 years of study, we carried out this project with the aim to breed new seedless cultivars by embryo rescue through three hybridization techniques: 1) development of the disease-resistant seedless cultivars using cross-breeding between seedless V. vinifera cultivars (susceptible to fungal diseases) and wild Chinese Vitis spp (resistant to fungal diseases); 2) crossing with two seedless cultivars, and 3) hybridization between grapes of different ploidy. There are many factors in the inducement of the embryo, and in this study, we focused on the effects of the crossing parents, media type, and sampling time on the germination and seedling survival rate.

\section{MATERIAL AND METHODS}

\section{Hybridization}

All grape plants were grown in a vineyard of the Xinjiang Development and Research Center of Grapes and Melons, located in Shanshan County, Xinjiang Uygur Autonomous Region of P.R. China. Eight- to 10-year-old plants were used and trained to trellis with a planting density of $1.0 \times 4.0 \mathrm{~m}$. Emasculation (Figure 1A) was conducted 3 days before anthesis, followed by washing and bagging of the inflorescence. Artificial pollination (Figure 1B) was conducted by using a mass of cotton with pollens collected earlier from the male parents, followed by immediate bagging and marking of the inflorescence (Figure 1C). The 12 crosscombinations were set (Table 1).

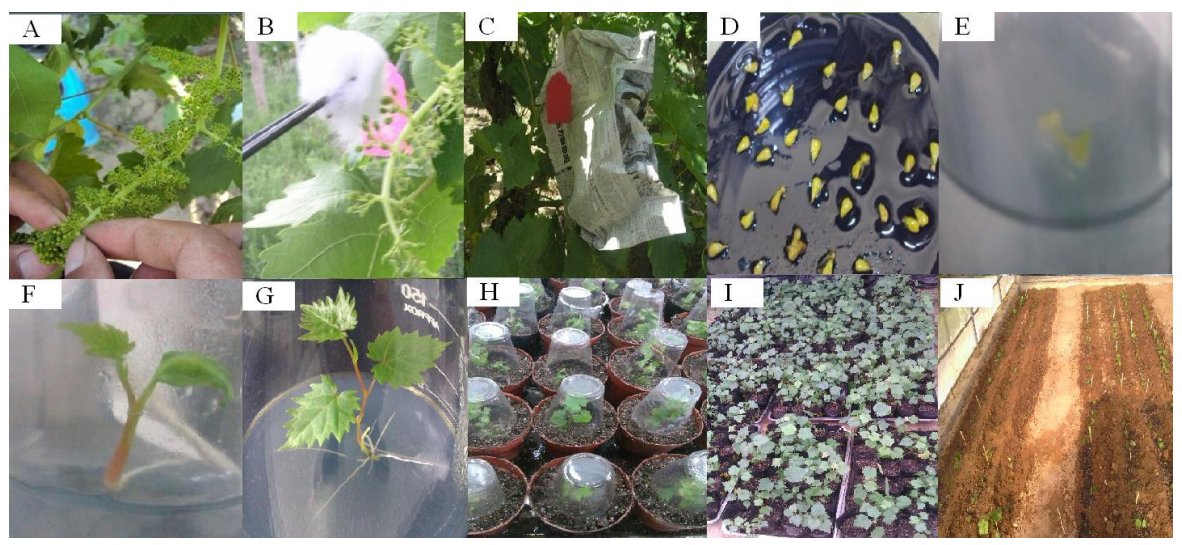

Figure 1. Embryo rescue procedure of seedless grape crosses. (A) Emasculation; (B) pollination; (C) fruits were bagged and marked; (D) ovules cultured in solid medium; (E) initial germination of embryo; (F) plantlet with true leaves; (G) whole plantlet developed from germinated embryos; (H and I) acclimatization and transplantation of hybrid seedlings; $(\mathbf{J})$ survived seedlings in nursery greenhouse. 


\begin{tabular}{|c|c|c|}
\hline Cross & Female characteristics & Male characteristics \\
\hline Flame Seedless x Beichun* & Vitis vinifera; stenospermic; diploid & $\begin{array}{l}V \text { vinifera } \mathrm{x} \text { Vitis amurensis hybrid; seeded; } \\
\text { diploid; resistant to downy mildew, anthracnose, } \\
\text { ripe rot and white rot }\end{array}$ \\
\hline Blush Seedless x Shuangyou* & $V$ vinifera ; stenospermic; diploid & $\begin{array}{l}\text { V. amurensis; seeded; diploid; } \\
\text { resistant to anthracnose }\end{array}$ \\
\hline Pink Seedless x Beichun* & V. vinifera ; stenospermic; diploid & $\begin{array}{l}V \text {. vinifera } \mathrm{x} V \text {. amurensis hybrid; seeded; diploid; } \\
\text { resistant to downy mildew, anthracnose, } \\
\text { ripe rot and white rot }\end{array}$ \\
\hline DA7 x Shuangyou* & $\begin{array}{l}\text { V. vinifera; hybrid of Delight } \mathrm{x} \\
\text { Emerald Seedless, stenospermic; diploid }\end{array}$ & $\begin{array}{l}\text { V. amurensis; seeded; diploid; } \\
\text { resistant to anthracnose }\end{array}$ \\
\hline Blush Seedless x Thompson Seedless** & V. vinifera ; stenospermic; diploid & $V$ vinifera ; stenospermic; diploid \\
\hline Pink Seedless x Flame Seedless** & V. vinifera ; stenospermic; diploid & V. vinifera ; stenospermic; diploid \\
\hline DA7 x Blush Seedless** & $\begin{array}{l}\text { V. vinifera; hybrid by Delight x } \\
\text { Emerald Seedless, stenospermic; diploid }\end{array}$ & $V$ vinifera ; stenospermic; diploid \\
\hline Thompson Seedless x Blush Seedless** & V. vinifera $;$ stenospermic; diploid & V. vinifera ; stenospermic; diploid \\
\hline Ruby Seedless x Black Olympia*** & V. vinifera ; stenospermic; diploid & $\begin{array}{l}\text { V. vinifera } \mathrm{x} \text { Vitis labrusca hybrid; } \\
\text { seeded; tetraploid }\end{array}$ \\
\hline DA7 x Jingyou*** & $\begin{array}{l}\text { V. vinifera; hybrid by Delight } \mathrm{x} \\
\text { Emerald Seedless, stenospermic; diploid }\end{array}$ & V. vinifera $\mathrm{x}$ V. labrusca hybrid; seeded; tetraploid \\
\hline Flame Seedless x Fujiminori*** & V. vinifera ; stenospermic; diploid & $V$. vinifera $\mathrm{x}$ V. labrusca hybrid; seeded; tetraploid \\
\hline Big black x Kyoho*** & V. vinifera ; stenospermic; diploid & $V$. vinifera $\mathrm{x}$ V. labrusca hybrid; seeded; tetraploid \\
\hline
\end{tabular}

Cross column means female parent $\mathrm{x}$ male parent; $* 2 \mathrm{X}$ seedless grape $\mathrm{x} 2 \mathrm{X}$ wild Chinese grape; $* * 2 \mathrm{X}$ seedless grape $\mathrm{x} 2 \mathrm{X}$ seedless grape; $* * * 2 \mathrm{X}$ seedless grape $\mathrm{x} 4 \mathrm{X}$ grape.

\section{Embryo rescue and plant development}

Immature fruits were collected at different times after pollination (Table 2) and surface-sterilized with $70 \%$ ethanol for $30 \mathrm{~s}$, followed by $0.1 \% \mathrm{HgCl}_{2}$ for $6 \mathrm{~min}$ and three washes in sterilized water. Ovules were excised and cultured in Erlenmeyer flasks containing embryo formation medium (MM4 + $500 \mathrm{mg} / \mathrm{L}$ mashed banana), with each flask containing 30 35 ovules (Figure 1D). The $\mathrm{pH}$ of the medium was adjusted to 6.0 before autoclaving. All cultures were grown at a temperature of $25^{\circ} \mathrm{C}$ under a 16 -h photoperiod with a light intensity of $40 \mu \mathrm{E} \cdot \mathrm{s}^{-1} \cdot \mathrm{m}^{-1}$ provided by a cool-white fluorescent light. Subculturing was performed at every 4 weeks. After 9 to 10 weeks of in vitro culture, embryos developed were recorded, excised from the ovules under a stereomicroscope, and then transferred onto germination media. After 4 weeks of culture, the germinated embryos (Figure 1E) were counted and transferred to the rooting media for plant regeneration (Figure 1F). Following 4 weeks of culture, the wellrooted clones (Figure 1G) were recorded and transplanted into pots containing a perlite-peatsoil mixture [3:1:1 (v/v)]. These pots were covered with plastic cups to maintain the initial humidity (Figure $1 \mathrm{H})$, and then the cups were uncovered gradually for plant hardening. The hardened plants were moved to a greenhouse with natural daylight for acclimatization (Figure 1I). The surviving progenies were used for establishment in soil (Figure 1J).

\section{Media}

The development medium: 100 ovules were mixed from 5 kinds of stenospermic grape (Pink Seedless, Blush Seedless, DA7, Ruby Seedless, Flame Seedless), and 20 ovules were 
Table 2. Effect of sampling times on ovule germination rate.

\begin{tabular}{|c|c|c|c|c|c|c|c|c|c|c|c|c|c|c|c|}
\hline \multirow[t]{2}{*}{ Cross } & \multicolumn{15}{|c|}{ Sampling time (day/month) } \\
\hline & $28 / 6$ & $1 / 7$ & $4 / 7$ & $7 / 7$ & $10 / 7$ & $13 / 7$ & $16 / 7$ & $19 / 7$ & $22 / 7$ & $25 / 7$ & $28 / 7$ & $31 / 7$ & $3 / 8$ & $5 / 8$ & $8 / 8$ \\
\hline Flame Seedless x Beichun* & 3.2 & 7.6 & 22.8 & 14.5 & 0 & & & & & & & & & & \\
\hline Blush Seedless x Shuangyou* & & & & & & & 0 & 13.2 & 30.4 & 3.3 & 0 & & & & \\
\hline Pink Seedless x Beichun* & & & & & & & 0 & 1.0 & 3.8 & 0 & 0 & & & & \\
\hline DA7 x Shuangyou* & & & & 0 & 0 & 3.6 & 0.2 & 0 & & & & & & & \\
\hline Blush Seedless x Thompson Seedless** & & & & & & & 0 & 3.2 & 24.7 & 9.3 & 0 & & & & \\
\hline Pink Seedless x Flame Seedless** & & & & & & & 0 & 1.9 & 7.6 & 2.3 & 0 & & & & \\
\hline DA7 x Blush Seedless** & & & & 0 & 0 & 1.9 & 0.4 & 0 & & & & & & & \\
\hline Thompson Seedless x Blush Seedless** & 0 & 0 & 0 & 0 & 0 & & & & & & & & & & \\
\hline Ruby Seedless x Black Olympia*** & & & & & & & & & 2.4 & 15.2 & 35.0 & 11.2 & 0 & & \\
\hline DA7 x Jingyou*** & & & & 0 & 3.2 & 30.4 & 21.9 & 0 & & & & & & & \\
\hline Flame Seedless x Fujiminori*** & 0 & 0 & 13.3 & 9.5 & 0 & & & & & & & & & & \\
\hline Big black x Kyoho*** & & & & & & & & & & & 0 & 1.2 & 11.4 & 16.2 & 3.1 \\
\hline
\end{tabular}

Cross column means female parent $\mathrm{x}$ male parent; $* 2 \mathrm{X}$ seedless grape $\mathrm{x} 2 \mathrm{X}$ wild Chinese grape; $* * 2 \mathrm{X}$ seedless grape $\mathrm{x} 2 \mathrm{X}$ seedless grape; $* * * 2 \mathrm{X}$ seedless grape $\mathrm{x} 4 \mathrm{X}$ grape.

collected and replicated three times. Two different media were used as the basal medium: 1) ER (Emershad and Ramming, 1994) medium and 2) MM4, a modified ER medium with macronutrients as follows: $235 \mathrm{mg} / \mathrm{L} \mathrm{Ca}\left(\mathrm{NO}_{3}\right)_{2} \cdot 4 \mathrm{H}_{2} \mathrm{O} ; 660 \mathrm{mg} / \mathrm{L} \mathrm{KNO} ; 75 \mathrm{mg} / \mathrm{L} \mathrm{KCl} ; 300 \mathrm{mg} / \mathrm{L} \mathrm{NH}_{4} \mathrm{NO}_{3}$; $1250 \mathrm{mg} / \mathrm{L} \mathrm{MgSO}_{4} \cdot 7 \mathrm{H}_{2} \mathrm{O} ; 760 \mathrm{mg} / \mathrm{L} \mathrm{NaH} \mathrm{PO}_{4} \cdot 2 \mathrm{H}_{2} \mathrm{O}$ (according to patent No. 200610043024.0, P.R. China); other components were all in accordance with ER; gibberellic acid (GA3); indole3-acetic acid (IAA); indole-3 butyric acid (IBA); plant growth regulators (PGRs); woody plant medium (WPM) (Lloyd and McCown, 1980). The medium with $0.1 \%$ activated carbon and 60 $\mathrm{g} / \mathrm{L}$ sucrose was supplemented with $0.5 \mathrm{mg} / \mathrm{L}$ GA3 plus $1.5 \mathrm{mg} / \mathrm{L}$ IAA or $500 \mathrm{mg} / \mathrm{L}$ mashed banana (Table 3). The germination medium: WPM and $0.2 \mathrm{mg} / \mathrm{L}$ 6-benzyladenine (6-BA). The rooting medium: MS, $0.1 \mathrm{mg} / \mathrm{L} \mathrm{IBA}$, and $0.4 \mathrm{mg} / \mathrm{L}$ 6-BA.

$\begin{aligned} & \text { Table 3. Effect of medium composition on embryo formation, germination and plant development (means } \pm \\
& \text { standard deviation). }\end{aligned}$
\begin{tabular}{lccc}
\hline Medium composition & Embryo formation (\%) & Embryo germination (\%) & Plant development (\%) \\
\hline ER & $11.3 \pm 2.2^{\text {abc }}$ & $91.2 \pm 3.2^{\mathrm{a}}$ & $79.0 \pm 2.0^{\mathrm{b}}$ \\
ER $+0.5 \mathrm{mg} / \mathrm{L} \mathrm{GA} 3+1.5 \mathrm{mg} / \mathrm{L} \mathrm{IAA}$ & $9.7 \pm 1.2^{\mathrm{bc}}$ & $86.3 \pm 2.8^{\mathrm{bc}}$ & $72.9 \pm 1.7^{\mathrm{c}}$ \\
ER $+500 \mathrm{mg} / \mathrm{L}$ mashed banana & $12.6 \pm 1.3^{\mathrm{ab}}$ & $92.6 \pm 2.6^{\mathrm{a}}$ & $88.5 \pm 1.0^{\mathrm{a}}$ \\
MM4 & $11.9 \pm 1.9^{\mathrm{abc}}$ & $91.4 \pm 1.2^{\mathrm{a}}$ & $79.4 \pm 1.4^{\mathrm{b}}$ \\
MM4 $+0.5 \mathrm{mg} / \mathrm{L} \mathrm{GA}+1.5 \mathrm{mg} / \mathrm{L}$ IAA & $9.3 \pm 1.5^{\mathrm{c}}$ & $83.1 \pm 2.7^{\mathrm{c}}$ & $67.2 \pm 1.0^{\mathrm{d}}$ \\
MM4 $+500 \mathrm{mg} / \mathrm{L}$ mashed banana & $13.2 \pm 0.6^{\mathrm{a}}$ & $90.7 \pm 2.2^{\mathrm{ab}}$ & $90.1 \pm 2.8^{\mathrm{a}}$ \\
\hline
\end{tabular}

Means within a row followed by different superscript letters are different at $\mathrm{P}=0.05$ ( $t$-test).

\section{Identification of nuclear-free character and ploidy level}

Marker-assisted selection now plays a prominent role in the field of plant breeding and cultivar improvement. Therefore, our group has carried out research in this field for breeding seedless grapes for over 10 years. We obtained an 18-bp oligomer, named probe No. 1 (5'-CCAGTTCGCCCGTAAATG-3'), as the DNA probe and used it to identify seedless genes of the hybrids from the seedless grape breeding program, via PCR assay (Wang and Lamikanra, 2002). The template DNAs were extracted from four-hybrid grape plants obtained from the crosses 'Flame Seedless x Beichun', 'Blush Seedless x Shuangyou', 'Pink Seedless x Beichun', 
and 'Blush Seedless $x$ Thompson Seedless', with reference to the modified CTAB method (Wang and Lamikanra, 2002). The presence of the approximately 590-bp-specific fragment suggested which grape vines were carriers of and expressed the seedless genes (Figure 2).

We identified the chromosome ploidy level of three-hybrid grape plants, which were from the crosses 'Ruby Seedless x Black Olympia', 'DA7 x Jingyou', and 'Big Black x Kyoho'. The identification was carried out with a ploidy analysis instrument (Partec, Germany) in the State Key Laboratory of Crop Genetic Improvement, Huazhong Agricultural University.

\section{RESULTS}

\section{Effect of genotype on in vitro embryo formation and plant development}

The responses of different cross-combinations to embryo rescue are shown in Table 4. Among the different genotypes, the productions of hybrid plants were significantly different. It ranged from 23.0\% (Ruby Seedless x Black Olympia) to only 1.1\% (Pink Seedless x Beichun). In 5 of 12 crosses (viz., 'DA7 x Shuangyou', 'Pink Seedless x Flame Seedless', 'DA7 x Blush Seedless', 'Thompson Seedless x Blush Seedless', and 'Flame Seedless x Fujiminori'), no seedlings survived.

\begin{tabular}{|c|c|c|c|}
\hline Cross & No. of ovules cultured & Embryo formation $(\%)$ & Plant development (\%) \\
\hline Flame Seedless x Beichun* & 225 & $22.8 \pm 1.2^{\mathrm{c}}$ & $12.9 \pm 0.8^{c}$ \\
\hline Blush Seedless x Shuangyou* & 450 & $30.4 \pm 2.6^{\mathrm{b}}$ & $10.7 \pm 1.0^{\mathrm{d}}$ \\
\hline Pink Seedless x Beichun* & 450 & $3.8 \pm 1.0^{\mathrm{f}}$ & $1.1 \pm 1.0^{\mathrm{f}}$ \\
\hline DA7 x Shuangyou* & 252 & $3.6 \pm 1.0^{\mathrm{f}}$ & - \\
\hline Blush Seedless x Thompson Seedless** & 300 & $24.7 \pm 2.0^{c}$ & $6.4 \pm 1.0^{\mathrm{e}}$ \\
\hline Pink Seedless x Flame Seedless** & 225 & $7.6 \pm 1.4^{\mathrm{e}}$ & - \\
\hline DA7 x Blush Seedless** & 294 & $1.9 \pm 1.1^{\mathrm{f}}$ & - \\
\hline Thompson Seedless x Blush Seedless** & 69 & - & - \\
\hline Ruby Seedless x Black Olympia*** & 375 & $35.0 \pm 4.6^{\mathrm{a}}$ & $23.0 \pm 2.0^{\mathrm{a}}$ \\
\hline DA7 x Jingyou $* * *$ & 225 & $35 \pm 2.3^{\mathrm{a}}$ & $15.7 \pm 1.4^{\mathrm{b}}$ \\
\hline Flame Seedless x Fujiminori*** & 192 & $13.3 \pm 3.0^{\mathrm{d}}$ & - \\
\hline Big black x Kyoho*** & 600 & $16.2 \pm 1.5^{\mathrm{d}}$ & $10.4 \pm 1.0^{\mathrm{d}}$ \\
\hline
\end{tabular}

Cross column means female parent $\mathrm{x}$ male parent; $* 2 \mathrm{X}$ seedless grape $\mathrm{x} 2 \mathrm{X}$ wild Chinese grape; $* * 2 \mathrm{X}$ seedless grape $\mathrm{x} 2 \mathrm{X}$ seedless grape; $* * * 2 \mathrm{X}$ seedless grape $\mathrm{x} 4 \mathrm{X}$ grape. Means within a row followed by different superscript letters are different at $\mathrm{P}=0.05$ ( $t$-test).

\section{Effect of sampling time on ovule germination rate}

The fruits were collected from June 28 to August 8 . The different cross-combinations got their highest ovule germination rate at different sampling times (Table 2). Based on our statistics, it resulted that the best sampling times for different combinations, in days after flowering (DAF), were as follows: 'Flame Seedless x Beichun' (39 DAF); 'Blush Seedless x Shuangyou' (54 DAF); 'Pink Seedless x Beichun' (54 DAF); 'DA7 x Shuangyou' (44 DAF); 'Blush Seedless x Thompson Seedless (54 DAF)'; 'Pink Seedless x Flame Seedless' (54 DAF); 'DA7 x Blush Seedless' (44 DAF); 'Ruby Seedless x Black Olympia' (63 DAF); 'DA7 x Jingyou' (44 DAF); 'Flame Seedless x Fujiminori' (39 DAF), and 'Big Black x Kyoho' (72 DAF). In addition, no ovules were obtained from the cross 'Thompson Seedless x Blush Seedless'. 


\section{Effect of media on embryo formation, germination, and plant development}

Medium composition significantly affected embryo formation and plant development (Table 3). The highest embryo formation rate (13.2\%) and plant development rate (90.1\%) were found when ovules were cultured in MM4 with $500 \mathrm{mg} / \mathrm{L}$ mashed banana. Adding mashed banana to both ER and MM4 improved the embryo formation rate and plant development rate. Conversely, the embryo formation rate and plant development rate were reduced by the addition of the plant growth regulators (PGRs), $0.5 \mathrm{mg} / \mathrm{L} \mathrm{GA}_{3}$ and $1.5 \mathrm{mg} / \mathrm{L} \mathrm{IAA}$. Therefore, we adopted the addition of $500 \mathrm{mg} / \mathrm{L}$ mashed banana to the MM4 medium as the development medium for embryo rescue.

\section{The result of identification of nuclear-free character and ploidy level}

Forty-five lines of 4 hybrids, obtained from the cross-combinations 'Flame Seedless x Beichun', 'Blush Seedless x Shuangyou', 'Pink Seedless x Beichun', and 'Blush Seedless x Thompson Seedless', were identified by probe No. 1 (5'-CCAGTTCGCCCGTAAATG-3'). Among them, 11 lines that had the 590-bp-specific band were tentatively considered as seedless varieties (Figure 2), and were named JW-1-1, JW-1-2, JW-1-3, JW-2-1, JW-2-2, JW-3-1, JW-4-1, JW-4-2, JW-4-3, JW-4-4, and JW-4-5.

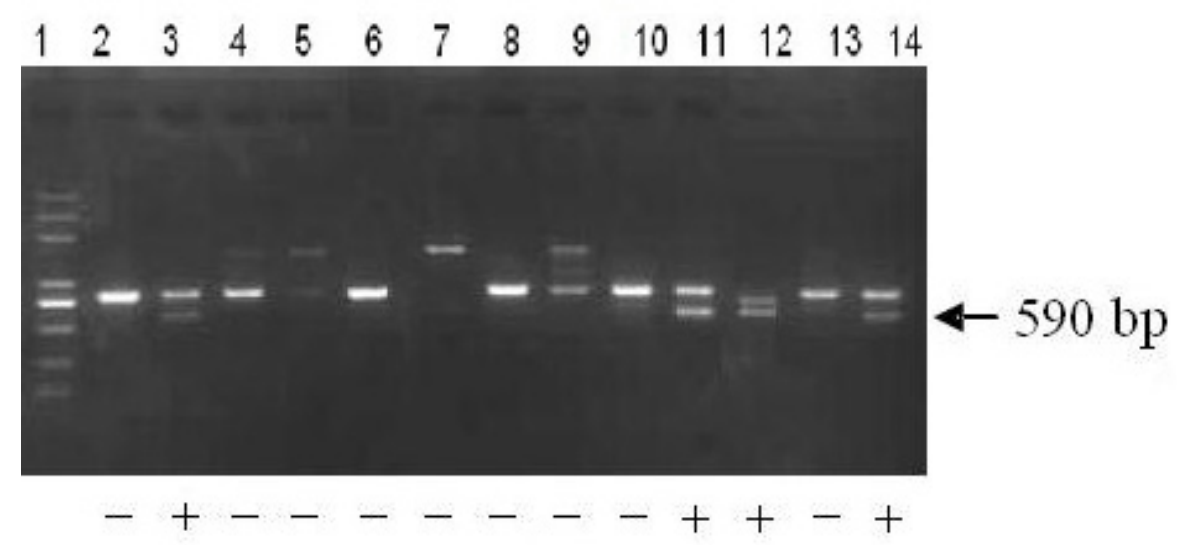

Figure 2. Amplified results of molecular probe No. 1 linked to seedlessness gene in hybrid strains. Lane $1=$ PCR marker; lanes 2 to $14=$ hybrid plants. $(+)=590$-bp-specific band present; $(-)=590$-bp-specific band absent.

One hundred and seventy-six lines of three-hybrid grape plants, obtained from the cross-combinations 'Ruby Seedless x Black Olympia', 'DA7 x Jingyou', and 'Big Black x Kyoho', were identified at the DNA ploidy level. The identification results showed that they displayed five different DNA ploidy levels: haploid, diploid, triploid, tetraploid, or aneuploid (Figure 3). Among the five lines, three lines were confirmed as triploid, named JW3-1, JW3-2, and JW3-3, and two lines were confirmed as haploid, named JW1-1 and JW1-2. In addition, judging from the appearance, the degrees of development of plants with different ploidy levels were also inconsistent (Figure 4). 

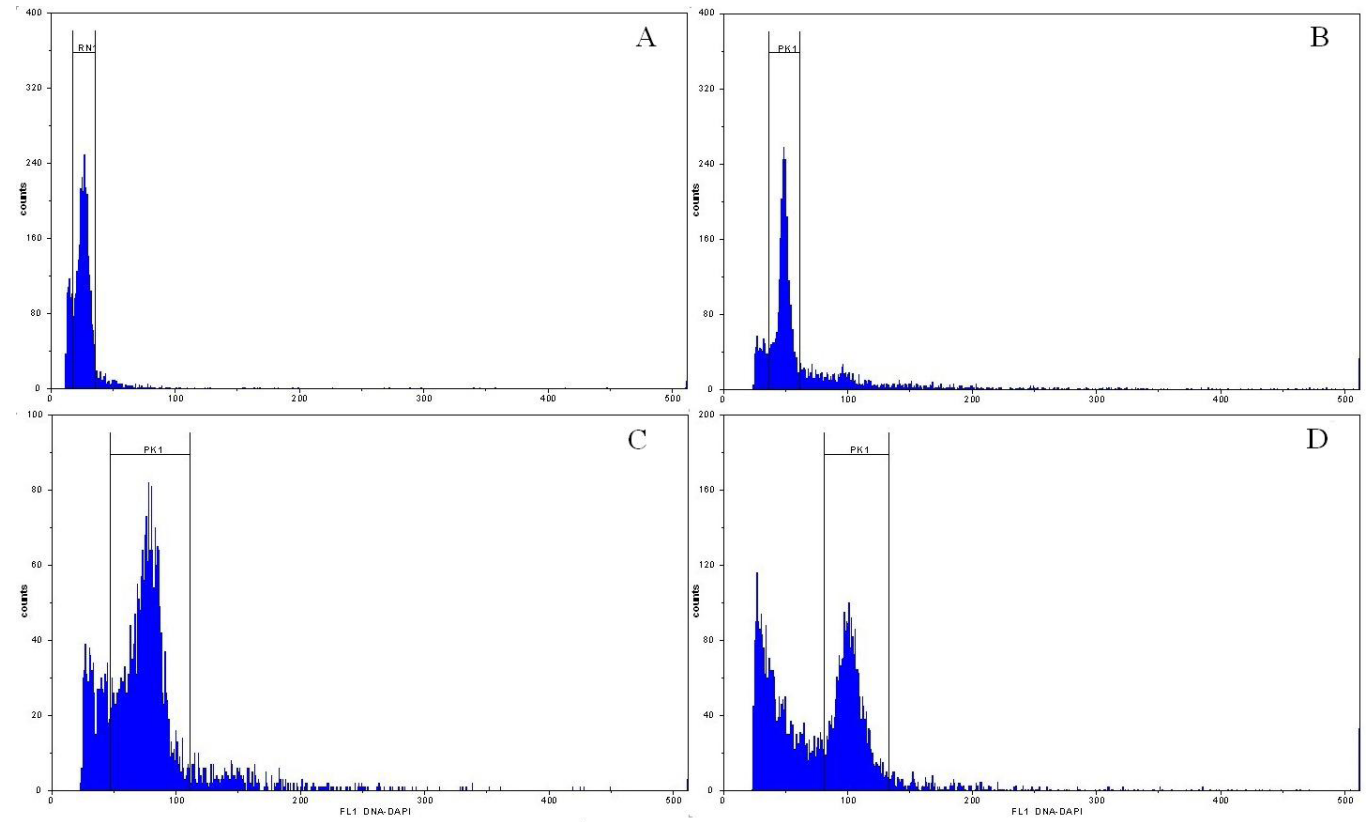

Figure 3. Flow cytometry histograms of hybrid seedlings from crosses between diploid and tetraploid grape cultivars: (A) haploid, (B) diploid, (C) triploid, and (D) tetraploid plants. Relative DNA content and ploidy levels were calculated from the ratio of sample peaks to that of the internal standard, "Xinyu" (a known diploid, 2x peak $=50.62$ ). Mode of diploid: (A) x peak $=26.80$; (B) $2 \mathrm{x}$ peak $=48.70$; (C) $3 \mathrm{x}$ peak $=75.42$; (D) $4 \mathrm{x}$ peak $=102.59$.

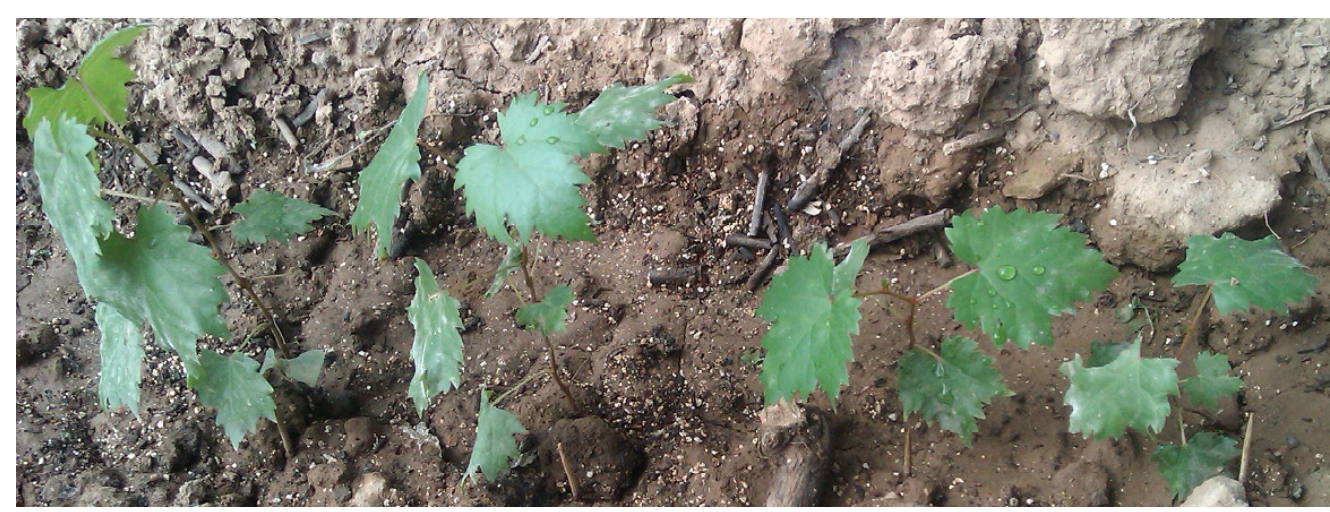

Figure 4. Grapes with different ploidy levels grew in field. They were haploid, diploid, triploid, and tetraploid plants from right to left, respectively.

\section{DISCUSSION AND CONCLUSIONS}

Consumer demand for seedless grapes has increased in the global market year by year. Thus, some grape breeders have strived to cultivate excellent seedless varieties by embryo rescue (Emershad and Ramming, 1984; Spiegle-Roy et al., 1985; Gray et al., 1990; Ponce 
et al., 2000; Bharathy et al., 2005; Tian et al., 2008; Tang et al., 2009; Singh et al., 2011). In 2000, Ramming et al. obtained a stenospermic hybrid (C41-5, interspecies cross $V$. vinifera $\mathrm{x}$ $V$. rotundifolia) by embryo rescue. In the same year, our group was also committed to creating new varieties of seedless grapes by the same technology, and we found some excellent characteristics of Chinese wild Vitis spp, such as fungal disease resistance, absence of the foxy flavor, and higher hybridization affinity with $V$. vinifer (He et al., 1991; He and Luo, 1994; Wang et al., 1995, 1998; Tian et al., 2008; Tang et al., 2009). Thus, in our study, two representative Chinese wild Vitis spp, 'Beichun' and 'Shuangyou', were also used as pollen parents to hybridize with $V$. vinifera. We obtained four hybrids from 'Flame Seedless x Beichun', 'Blush Seedless x Shuangyou', 'Pink Seedless x Beichun', and 'Blush Seedless x Thompson Seedless'. They were identified by probe No. 1 (5'-CCAGTTCGCCCGTAAATG-3') (Wang and Lamikanra, 2002). Among them, 11 lines that had the 590-bp-specific band were tentatively considered as seedless varieties (Figure 2).

In addition, fostering triploid grapes is also an effective way to obtain new seedless grape varieties. In previous studies, the embryo rescue technique was used to breed triploid grapes (Yamashita et al., 1998; Bessho et al., 2000; Bharathy et al., 2005; Tian et al., 2008; Sun et al., 2011). In this study, we set four crosses with $2 \mathrm{X}$ x $4 \mathrm{X}$ and obtained triploid hybrid seedlings from 'Ruby Seedless x Black Olympia', 'DA7 x Jingyou', and 'Big Black x Kyoho'. The results of ploidy level identification showed that there were three lines confirmed as triploid and two lines confirmed as haploid (Figure 3), and the others were diploid, tetraploid, or aneuploidy plants.

The effects of genotype on embryo rescue have been reported in earlier studies (Burger and Goussard, 1996; Liu et al., 2003; Bharathy et al., 2005; Tian et al., 2008; Guo et al., 2010). In the present study, we found that embryo formation, embryo germination, and plant development varied greatly among different cross-combinations. This was consistent with previous studies. We obtained 7 hybrids from 12 cross-combinations. Among the different genotypes, the productions of hybrid plants were significantly different, ranging from $23.0 \%$ (Ruby Seedless x Black Olympia) to only 1.1\% (Pink Seedless x Beichun). This might have been related to the hybridization affinity and differences in genetic compatibilities between parental germplasms, which was consistent with the opinion of Sun et al. (2011).

Ovule germination rate depends largely on the development level of the embryo. Thus, the sampling time is a very important factor in the embryo rescue procedure. The different cross-combinations got their highest ovule germination rate at different sampling times. "Days after flowering" is an indicator commonly used for sampling time. Thus, different DAF indicators were proposed, such as 43 or 69 DAF (Spiegel-Roy et al., 1985), 42 or 70 DAF (Emershad et al., 1989), 40 or 60 DAF (Gray et al., 1990), 52 or 66 DAF (Tsolova, 1990), 56 DAF (Ponce et al., 2002), and 40 DAF (Bharathy et al., 2003). In this experiment, we got the best sampling times for different combinations: 'Flame Seedless x Beichun' (39 DAF); 'Blush Seedless x Shuangyou' (54 DAF); 'Pink Seedless x Beichun' (54 DAF); 'DA7 x Shuangyou' (44 DAF); 'Blush Seedless x Thompson Seedless (54 DAF)'; 'Pink Seedless x Flame Seedless' (54 DAF); 'DA7 x Blush Seedless' (44 DAF); 'Ruby Seedless x Black Olympia' (63 DAF); 'DA7 x Jingyou' (44 DAF); 'Flame Seedless x Fujiminori' (39 DAF), and 'Big Black $x$ Kyoho' (72 DAF). It indicated that the torpedo stage of embryo of different cultivars did not occur simultaneously, so the behavior was individual. In addition, we got no ovules from the cross 'Thompson Seedless x Blush Seedless', indicating that it might have been too late to obtain its proper sampling time. 
The embryo rescue of the hybridization progeny consists of three phases, which are further embryo development in the ovule, embryo germination, and plant development. The composition of the media was also found to be a critical factor for in vitro embryo rescue of seedless grapes. In the present study, we found that addition of $500 \mathrm{mg} / \mathrm{L}$ mashed banana to both ER and MM4 as a development medium significantly improved the plant development rate. It might be related with the various nutrients necessary for plant development contained in bananas. Conversely, it was reduced by addition of PGRs $\left(0.5 \mathrm{mg} / \mathrm{L} \mathrm{GA}_{3}+1.5 \mathrm{mg} / \mathrm{L} \mathrm{IAA}\right)$ (Table 4$)$. This was in accordance with the earlier findings by Liu et al. (2003). Palmer (2002) also obtained similar results in Vigna, in that a medium containing MS basal nutrients with $88 \mathrm{mM}$ sucrose, $500 \mathrm{mg} / \mathrm{L}$ casein hydrolysate, and $8 \mathrm{~g} / \mathrm{L}$ agar, but devoid of PGRs, was found to be the best for germination of immature embryos for all four Vigna species investigated. The induction might be due to the imbalance of auxins and cytokinins. However, in previous studies, GA 3 and IAA were proven to enhance in vitro embryo rescue efficiency (Gray et al., 1990; Gribaudo et al., 1993; Yamashita et al., 1998; Guo et al., 2004; Valdez, 2005). These results were inconsistent with ours. That might have been caused by the type and quantity of the application of PGRs.

In fact, breeding for stenospermic grapes by embryo rescue is a long-term task. This study is only a preliminary report. Other factors, such as the addition of mineral nutrients and PGRs to the medium, could also influence the breeding efficiency through complex interactions. With the increasing number of progenies in our laboratory, further studies on various parameters are in progress, and the further identification and screening of the plants with target traits in the field is our next task. The results obtained could clearly indicate the feasibility and perspective of our protocol.

\section{ACKNOWLEDGMENTS}

Research supported by the Project of Special Fund for Agro-Scientific Research in the Public Interest (\#200903044-4) and by the Earmarked Fund for China Agriculture Research System (Grant \#CARS-30-yz-7). The study was performed in the College of Horticulture, Northwest A\&F University, Yangling 712100, Shaanxi, P.R. China; the Key Laboratory of Horticultural Plant Biology and Germplasm Innovation in Northwest China, Ministry of Agriculture, Yangling, Shaanxi 712100, P.R. China; the State Key Laboratory of Crop Stress Biology in Arid Areas, Northwest A\&F University, Yangling 712100, Shaanxi, P.R. China, and the State Key Laboratory of Crop Genetic Improvement, Huazhong Agricultural University, Wuchang 430070, Hubei, P.R. China.

\section{REFERENCES}

Alleweldt G and Possingham JV (1988). Progress in grapevine breeding. Theor. Appl. Genet. 75: 669-673.

Bessho H, Miyake M and Kondo M (2000). Grape breeding in Yamanashi, Japan present and future. Acta Hortic. 538: 493-496.

Bharathy PV, Karibasappa GS and Biradar AB (2003). Influence of pre-bloom sprays of benzyladenine on in vitro recovery of hybrid embryos from crosses of Thompson seedless and 8 seeded varieties of grape (Vitis spp.). Vitis 42: 199-202.

Bharathy PV, Karibasappa US, Patil SG and Agrawal DC (2005). In ovulo rescue of hybrid embryos in Flame Seedless grapes - Influence of pre-bloom sprays of benzyladenine. Sci. Hortic. 106: 353-359.

Burger P and Goussard PG (1996). In vitro culture of ovules and embryos from seedless grapes (Vitis vinifera L.). S. Afr. J. Enol. Vitic. 17: 31-37.

Emershad RL and Ramming DW (1984). In-ovulo embryo culture of Vitis vinifera LCV 'Thompson seedless'. Am. J. Bot. 71: 873-877. 
Emershad RL and Ramming DW (1994). Somatic embryogenesis and plant development from immature zygotic embryos of seedless grapes (Vitis vinifera L.). Plant Cell Rep. 14: 6-12.

Emershad RL, Ramming DW and Serpe MD (1989). In ovulo embryo development and plant formation from stenospermic genotypes of Vitis vinifera. Am. J. Bot. 76: 397-402.

Gray DJ, Mortensen JA, Benton CM, Durham RE, et al. (1990). Ovule culture to obtain progeny from hybrid seedless bunch grapes. J. Am. Soc. Hortic. Sci. 115: 1019-1024.

Gribaudo I, Zanetti R, Botta R, Vallania R, et al. (1993). In ovulo embryo culture of stenospermocarpic grapes. Vitis 32: 9-14.

Guo YS, Gao XY, Zhao YH and Guo XW (2004). Preliminary report on the embryo rescue technique in Venus Seedless grape. Sino-overseas Grapevine Wine 3: 6-8.

Guo YS, Li K, Zhao YH and Guo XW (2010). Study of embryo rescue on cross between tetraploid table grape (Vitis vinifera L.) and Vitis amurensis Rupr. 2nd Conf. Hortic. Sci. Technol.147-149.

He PC and Luo GG (1994). Grapevine Science. Chinese Agricultural Press, Beijing.

He PC, Wang YJ, Wang GY, Ren ZB, et al. (1991). The studies on the disease resistance of Chinese wild Vitis species. Agric. Sci. China 24: 50-56.

Liu HN and Li H (2004). Studies on the resistance of Uncinula necator and Plasmopara viticola of Vitis vinifera. J. Northeast Agric. Univ. 35: 302-308.

Liu HN, Li CY and Wu GY (2002). Study on the resistance of Vitis vinifera to anthracnose disease. J. Hubei Agric. Coll. 22: $210-212$.

Liu SM, Sykes SR and Clingeleffer PR (2003). Improved in ovulo embryo culture for stenospermocarpic grapes (Vitis vinifera L.). Aust. J. Agric. Res. 54: 869-876.

Lloyd GB and McCown BH (1980). Commercially-feasible micropropagation of mountain laurel, Kalmia latifolia, by use of shoot-tip culture. Proc. Int. Plant Propag. Soc. 30: 421-437.

Palmer JL, Lawn RJ and Adkins SW (2002). An embryo-rescue protocol for Vigna interspecific hybrids. Aust. J. Bot. 50: 331-338.

Ponce MT, Agüero CB, Gregori MT and Tizio R (2000). Factors affecting the development of stenospermic grape (Vitis vinifera L.) embryos cultured in vitro. Acta Hortic. 528: 667-671.

Ponce MT, Guinazu ME and Tizio R (2002). Brief Note Improved in vitro embryo development of stenospermic grape by putrescine. Biocell 26: 263-266.

Ramming DW and Emershad RL (1982). In ovulo embryo culture of seeded and seedless Vitis vinifera L. HortScince 17: 487.

Ramming DW, Emershad RL and Tarailo R (2000). A stenospermocarpic seedless Vitis vinifera $\mathrm{x}$ Vitis rotundifolia hybrid developed by embryo culture. HortScience 35: 732-734.

Singh NV, Singh SK and Singh AK (2011). Standardization of embryo rescue technique and bio-hardening of grape hybrids (Vitis vinifera L.) using Arbuscular mycorrhizal fungi (AMF) under sub-tropical conditions. Vitis 50: 115-118.

Spiegle-Roy P, Sahar PN and Baron J (1985). In vitro culture and plant formation from grape cultivars with abortive ovules and seeds. J. Am. Soc. Hortic. Sci. 110: 109-112.

Stout AB (1936). Seedlessness in grapes. New York State Agriculture Experimental Station. Tech. Bull. 238.

Sun L, Zhang GJ, Yan AL and Xu HY (2011). The study of triploid progenies crossed between different ploidy grapes. Afr. J. Biotechnol. 10: 5967-5971.

Tang DM, Wang YJ, Cai JS and Zhao RH (2009). Effects of exogenous application of plant growth regulators on the development of ovule and subsequent embryo rescue of stenospermic grape (Vitis vinifera L.). Sci. Hortic. 120: 51-57.

Tian LL, Wang YJ, Niu L and Tang DM (2008). Breeding of disease-resistant seedless grapes using Chinese wild Vitis spp. I. In vitro embryo rescue and plant development. Sci. Hortic. 117: 136-141.

Tsolova V (1990). Obtaining plants from crosses of seedless grapevine varieties by means of in vitro embryo culture. Vitis 29: $1-4$.

Valdez JG (2005). Immature embryo rescue of grapevine (Vitis vinifera L.) after an extended period of seed trace culture. Vitis 44: 17-23.

Wang YJ and Lamikanra O (2002). Application and synthesis on the DNA probe for detecting seedless genes in grapevine. J. Northwest Sci. -Tech. Univ. Agr. For. 30: 25-46.

Wang YJ, Liu Y, He P, Chen J, et al. (1995). Evaluation of foliar resistance to Uncinula necator in Chinese wild Vitis species. Vitis 34: 159-164.

Wang YJ, Liu Y, He P, Lamikanra O, et al. (1998). Resistance of Chinese Vitis species to Elsinoë ampelina (de Bary) Shear. HortScience 33: 123-126.

Yamashita H, Shigehara I and Haniuda T (1998). Production of triploid grapes by in ovulo embryo culture. Vitis 37: 113-117. 